\title{
Clinical Effects and Radiological Results of Vertebroplasty: Over a 2-year Follow-Up Period
}

\author{
Han Ga Wi Nam, Je Hoon Jeong, II Young Shin, Seung-Myung Moon, Hyung Sik Hwang \\ Department of Neurosurgery, Dongtan Sacred Heart Hospital, College of Medicine Hallym University, \\ Hwaseong, Republic of Korea
}

\begin{abstract}
Objective: We investigated the association between clinical and radiological results and assessed the radiological changes according to the distribution pattern and amount of injected cement after vertebroplasty.

Methods: Two hundred and one patients underwent vertebroplasty; of these, 15 were follow up for more than 2 years. For radiological analysis, we grouped the patients according to cement distribution as follows: group 1, unilateral, unilateral distribution of cement; group 2, bilateral-uneven, bilateral distribution of cement but separated mass; and group 3, bilateral-even, bilateral single mass of cement. To compare radiologic with clinical results, we assessed the visual analogue scale (VAS) score, amount of injected cement, bone mineral density (BMD), postoperative and follow-up vertebral body compression ratios, and postoperative and follow-up kyphotic angles.

Results: There were $4(26.7 \%)$ patients in group $1,6(40.0 \%)$ in group 2, and $5(33.3 \%)$ in group 3 . The mean VAS score was 5.2 preoperatively, 1.8 postoperatively, and 3.2 at 2-year follow-up. The 2-year follow-up compression ratio was better in patients with even distribution of injected cement (group 2 and 3) than group 1. However, it was not statistically insignificant $(p>0.05)$. The follow-up kyphotic angle was more aggravated in the group 1 than in the other groups $(p<0.05)$.

Conclusion: Our study showed that vertebroplasty had a beneficial effect on pain relief, particularly in the immediate postoperative stage. The augmented spine tended to be more stable in the cases with increased amount and more even distribution of injected cement.
\end{abstract}

Key Words: Vertebroplasty $\cdot$ Polymethyl methacrylate $(\mathrm{PMMA}) \cdot$ Osteoporotic fracture $\cdot$ Compression fracture

\section{INTRODUCTION}

Vertebroplasty, a surgical procedure involving the injection of polymethyl methacrylate (PMMA) into a collapsed vertebral body ${ }^{6}$, was first described in 1987 by Pierre Galibert and Hervé Deramond for the treatment of symptomatic or aggressive vertebral angioma ${ }^{15}$. This technique has received significant attention and several studies related to the treatment of vertebral osteoporotic fractures have been published ${ }^{4,5,12,15,19)}$.

Pain relief and stabilization of collapsed vertebrae are the goals of this procedure. Several previous studies revealed that

- Received: October 4, 2012 - Revised: November 12, 2012

- Accepted: December 14, 2012

Corresponding Author: Je Hoon Jeong, M.D.

Department of Neurosurgery, Dongtan Sacred Heart Hospital, College of Medicine, Hallym University, 40 Sukwoo-dong, Hwaseong, Gyenggi-Do 445-170, Republic of Korea.

Tel: +82-31-8086-2810, Fax: +82-31-8086-2039,

E-mail: neuri71@gmail.com this goal was achieved immediately after treatment ${ }^{18)}$. However, long-term effectiveness is still questioned ${ }^{2,9,10)}$. Furthermore, there are controversies regarding the optimal volume and distribution of the injected cement, and the association between clinical improvement and radiological changes ${ }^{18)}$.

The purpose of this study was to assess the clinical and radiological results, elucidate the association between these results, and investigate radiological changes according to the distribution pattern and amount of injected cement after vertebroplasty.

\section{MATERIALS AND METHODS}

\section{Patients}

From January 2005 through October 2010, we performed vertebroplasty in 201 patients. Inclusion criteria were osteoporotic fracture with $5-20 \%$ canal encroachment and bone mineral density less than -3.0. Exclusion criteria included combined neurological deficits, pathological fractures, and un- 
stable vertebral fractures involving the middle or posterior column. In patients $<80$ years of age, we treated preoperatively with postural reduction for approximately 2 weeks; in patients $>80$ years of age, we performed vertebroplasty immediately after the onset. Fifteen of the 201 patients who underwent vertebroplasty were available for follow-up for more than 2 years and underwent follow-up radiography at 6,12 , and 24 months after the procedure. We reviewed the radiological and clinical data retrospectively.

\section{Vertebroplasty technique}

The patients were placed in a prone position. An 11 Gage vertebroplasty needle was inserted via a transpedicular approach by using Siremobil Iso-C3D (Siemens Medical Solutions, Erlangen, Germany). The needle was advanced through the pedicle, sloping anteriorly, medially, and caudally. The needle tip was placed at the anterior one-third of the vertebral body. Once the needle was placed inside the vertebral body, the liquid and powder components of PMMA were mixed and injected steadily at $1.5 \mathrm{cc}$ per minute through the needle under fluoroscopic guidance. Cement injection was performed under continuous fluoroscopic monitoring on lateral view, with close attention to the posterior margin of the vertebral body and the epidural space. During PMMA injection, frequent fluoroscopic controls were required to ensure that the material remained within the vertebral body without migrating into the surrounding venous plexus. Injection was terminated when the vertebral body was adequately filled or when the cement reached the posterior quarter of the vertebral body. After vertebro- plasty, the patients rested in a supine position for 3-4 hours.

\section{Imaging assessment}

We measured preoperative and postoperative vertebral body compression ratios (so-called wedge deformity), by calculating the anterior-posterior (AP) ratio, the Beck ${ }^{23)}$ Index (Fig. 1-A), and wedge angle (kyphotic angle), by measuring the angle between the superior endplate of the vertebral body above and
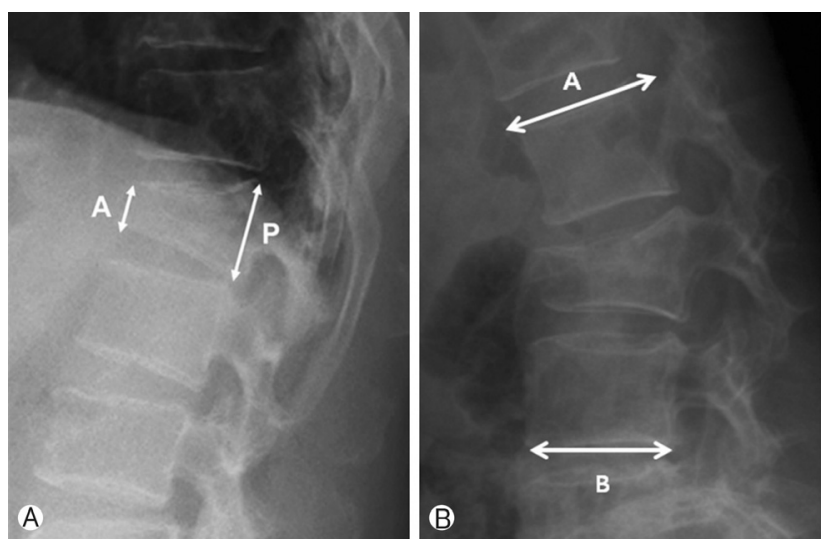

Fig. 1. Measured factors. (A) Compression ratio (A: anterior, P: posterior). The anterior-posterior (AP) ratio of the fractured vertebra calculated as the height of the anterior wall (A) divided by that of the posterior wall (P). A smaller AP ratio implies a greater degree of compression or wedge deformity. (B) Vertebral wedge angle (kyphotic angle). The angle between the superior endplate of the vertebral body above and the inferior endplate of the vertebral body below the fractured vertebra on the lateral radiograph.
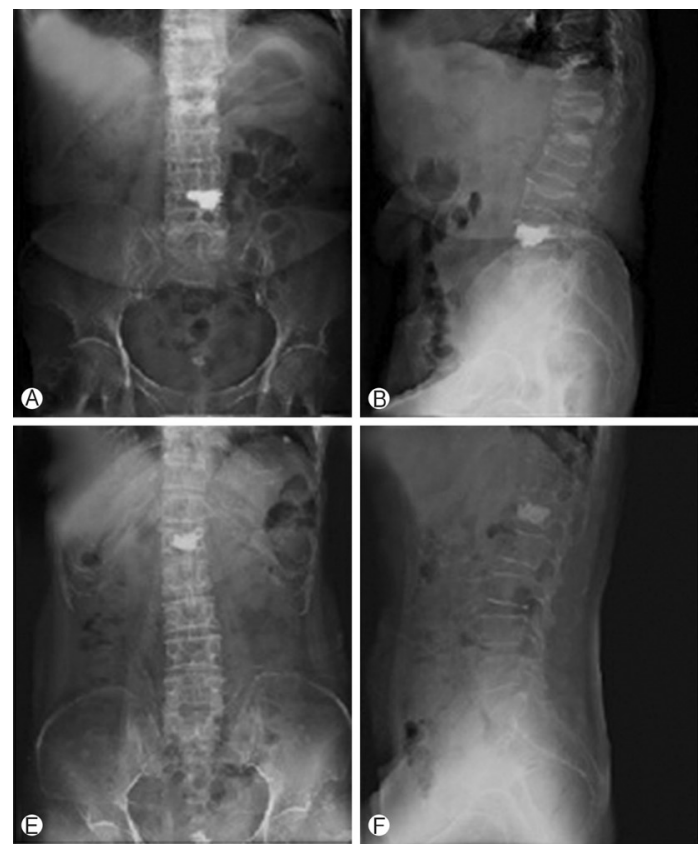
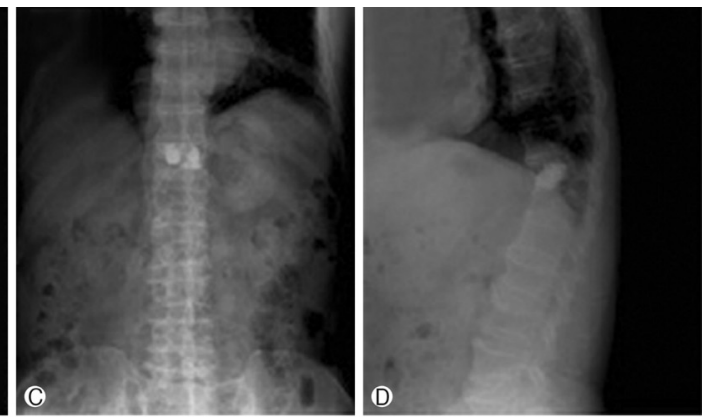

Fig. 2. The pattern of injected cement was divided into 3 groups: group 1, unilateral, unilateral distribution of cement (A, B); group 2, bilateral-uneven, bilateral distribution of cement but separated mass (C, D); and group 3 , bilateral-even, bilateral single mass of cement $(E, F)$. 
the inferior endplate of the vertebral body below the fractured vertebra on the lateral radiograph ${ }^{1)}$ (Fig. 1-B). For analysis of the injected cement pattern, we grouped the patients according to cement distribution as follows: group 1, unilateral, unilateral distribution of cement; group 2, bilateral-uneven, bilateral distribution of cement but separated mass; and group 3 , bilateral-even, bilateral single mass of cement and also according to the presence of cement leakage as follows: posterior, paravertebral: anterior or lateral to the vertebral body, foraminal, and intravascular ${ }^{24)}$ (Fig. 2). Follow-up radiography was performed at 6,12 , and 24 months after the procedure.

\section{Statistical analysis}

The SPSS version 12.0 statistical package was utilized for statistical analyses. Data were represented as mean \pm standard deviation (SD) and p-values less than 0.05 were considered statistically significant. The Pearson correlation test was used to analyze the differences between the visual analogue scale (VAS) and other parameter changes, and the Kruskal-Wallis test was used to analyze the differences in radiological measurements at preoperation and postoperation, 6 months, 12 months, and 24 months.

\section{RESULTS}

Male to female patient ratio was 2:13. The mean age of the patients was 75.9 years (range, 55-90 years). The locations and numbers of the treated vertebrae were as follows: $\mathrm{T} 7=1, \mathrm{~T} 11$ $=2, \mathrm{~T} 12=2, \mathrm{~L} 1=3, \mathrm{~L} 2=3, \mathrm{~L} 3=1, \mathrm{~L} 4=2, \mathrm{~L} 5=1$. Mean $\mathrm{T}$ score was -3.8 and mean amount of injected cement was 3.5

Table 1. Demography of patients

\begin{tabular}{|c|c|c|c|c|c|c|c|c|c|c|c|c|c|c|c|c|}
\hline \multirow{2}{*}{$\begin{array}{l}\text { Patient } \\
\text { No }\end{array}$} & \multirow{2}{*}{ Age } & \multirow{2}{*}{ Sex } & \multirow{2}{*}{$\begin{array}{c}\text { Type of Cement } \\
\text { Distribution }\end{array}$} & \multicolumn{3}{|c|}{ VAS } & \multicolumn{5}{|c|}{ Compression Ratio } & \multicolumn{5}{|c|}{ Kyphotic Angle $\left({ }^{\circ}\right)$} \\
\hline & & & & Pre OP & Post OP & Follow up & Pre OP & Post OP & 6 month & 1 year & 2 year & Pre OP & Post OP & 6 month & 1 year & 2 year \\
\hline 1 & 70 & $\mathrm{~F}$ & 2 & 6 & 3 & 5 & 43 & 22 & 22.0 & 26.0 & 36.0 & 17 & 10 & 10 & 10 & 13 \\
\hline 2 & 86 & $\mathrm{~F}$ & 1 & 5 & 2 & 2 & 30 & 17 & 19.0 & 25.0 & 25.0 & 11.7 & 9.8 & 9.5 & 9.7 & 11.5 \\
\hline 3 & 71 & $\mathrm{~F}$ & 3 & 6 & 2 & 5 & 43 & 26 & 29.0 & 33.0 & 33.0 & 10.2 & 7.4 & 7.3 & 8 & 7.8 \\
\hline 4 & 78 & M & 2 & 6 & 2 & 3 & 20.9 & 17 & 20.0 & 20.0 & 20.0 & 6.5 & 3.7 & 3.7 & 2.6 & 2.4 \\
\hline 5 & 84 & $\mathrm{~F}$ & 3 & 5 & 2 & 4 & 42 & 35 & 35.0 & 35.0 & 35.0 & 7.7 & 7.3 & 7.5 & 8.4 & 6.3 \\
\hline 6 & 90 & $\mathrm{~F}$ & 2 & 6 & 2 & 4 & 54 & 39 & 39.0 & 40.0 & 42.0 & 10.3 & 5.3 & 5.7 & 4.8 & 5.5 \\
\hline 7 & 55 & $M$ & 2 & 7 & 2 & 8 & 31 & 12 & 12.0 & 12.0 & 13.0 & 6.8 & 2.1 & 1.8 & 1.2 & 2 \\
\hline 8 & 80 & $F$ & 3 & 4 & 1 & 2 & 48 & 25 & 25.0 & 29.0 & 29.0 & 4 & 3.3 & 1.8 & 3.4 & 3.4 \\
\hline 9 & 69 & $\mathrm{~F}$ & 3 & 3 & 1 & 3 & 49 & 24 & 38.0 & 38.0 & 38.0 & 5.36 & 1.7 & 2.4 & 0.8 & 1.6 \\
\hline 10 & 79 & $\mathrm{~F}$ & 2 & 4 & 1 & 0 & 41 & 29 & 29.0 & 30.0 & 30.0 & 24 & 20.4 & 20.7 & 21.4 & 19.8 \\
\hline 11 & 78 & $\mathrm{~F}$ & 2 & 5 & 1 & 3 & 38 & 20 & 20.0 & 20.0 & 20.0 & 6.9 & 7.4 & 7.8 & 7.8 & 7.8 \\
\hline 12 & 74 & $F$ & 3 & 5 & 2 & 2 & 48.5 & 35 & 30.0 & 30.0 & 30.0 & 8.2 & 4 & 4.6 & 6.7 & 5.4 \\
\hline 13 & 90 & $\mathrm{~F}$ & 1 & 4 & 2 & 2 & 27 & 23 & 32.0 & 32.0 & 32.0 & 7.7 & 0 & 2.6 & 2.4 & 2.4 \\
\hline 14 & 75 & $\mathrm{~F}$ & 1 & 5 & 2 & 1 & 50 & 33 & 38.0 & 41.0 & 56.0 & 12 & 4.9 & 5.4 & 6 & 8 \\
\hline 15 & 79 & $\mathrm{~F}$ & 1 & 8 & 3 & 4 & 43 & 28 & 28.0 & 29.0 & 30.0 & 4.2 & 6.6 & 8.19 & 4.2 & 5.1 \\
\hline
\end{tabular}

VAS: visual analogue scale, OP: operation, Type of Cement Distribution: 1-unilateral, unilateral distribution of cement; 2-bilateral, uneven and bilateral distribution of cement but separated mass; 3-bilateral, even and bilateral single mass of cement.

Table 2. Correlations between bone factors and other parameter changes

\begin{tabular}{lcccc}
\hline Changes & Post operation Compression ratio & Follow up Compression ratio & Post operation Kyphotic angle & Follow up Kyphotic angle \\
\hline Amount of PMMA & 0.370 & $0.035^{*}$ & 0.484 & 0.098 \\
BMD & 0.557 & 0.808 & 0.723 & 0.913 \\
\hline
\end{tabular}

"statically significance $(p<0.05)$, VAS: visual analogue scale

Table 3. Correlations between VAS and other parameter changes

\begin{tabular}{lccccc}
\hline \hline & $\begin{array}{c}\text { Amount of } \\
\text { PMMA }\end{array}$ & $\begin{array}{c}\text { Post operation } \\
\text { Compression ratio }\end{array}$ & $\begin{array}{c}\text { Follow up } \\
\text { Compression ratio }\end{array}$ & $\begin{array}{c}\text { Post operation } \\
\text { Kyphotic angle }\end{array}$ & $\begin{array}{c}\text { Follow up } \\
\text { Kyphotic angle }\end{array}$ \\
\hline Post operation VAS & 0.598 & 0.915 & 0.331 & 0.557 & 0.193 \\
Follow up VAS & 0.449 & 0.142 & 0.781 & 0.866 & 0.162 \\
\hline
\end{tabular}

VAS: visual analogue scale 
cc. The number of patients in group 1 was $4(26.7 \%)$, group 2 was $6(40.0 \%)$, and group 3 was 5 (33.3\%). There were no cases of re-fracture at the surgical site, but fractures adjacent to the surgical site occurred in 3 cases (18.75\%) and fractures remote to the surgical site occurred in 2 cases (13.3\%) (Table 1).

We investigated the relationship between bone factors (amount of PMMA and bone mineral density) and other factors. There was statistically significant correlation between amount of PMMA and follow up compression ratio (Table 2). Mean postoperative and 2-year follow-up of the VAS were $1.8( \pm 0.6)$ and $3.2( \pm 1.9)$, respectively (Fig. 3). However, there were no correlations between VAS and radiologic factor changes (Table 3).

Total postoperative and 2-year follow-up compression mean ratios were $-15.0 \%$ and $6.7 \%$, respectively. Mean postoperative and 2-year follow-up changes in the compression ratio of the vertebral body height in group 1 were $-12.3 \%$ and $13.25 \%$, group 2 were $-14.7 \%$ and $3.7 \%$, and group 3 were $-17.5 \%$ and

$5.0 \%$, respectively. The 2-year follow-up compression ratio was better in patients with even distribution of injected cement (group 2 and 3) than group 1. Unfortunately, it was not statisti-

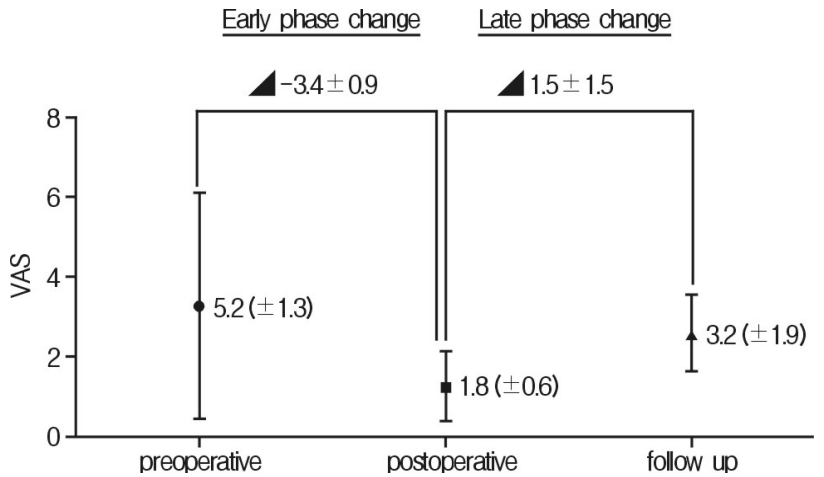

Fig. 3. Changes of VAS score at the preoperative, postoperative, and 2-year follow-up stages.

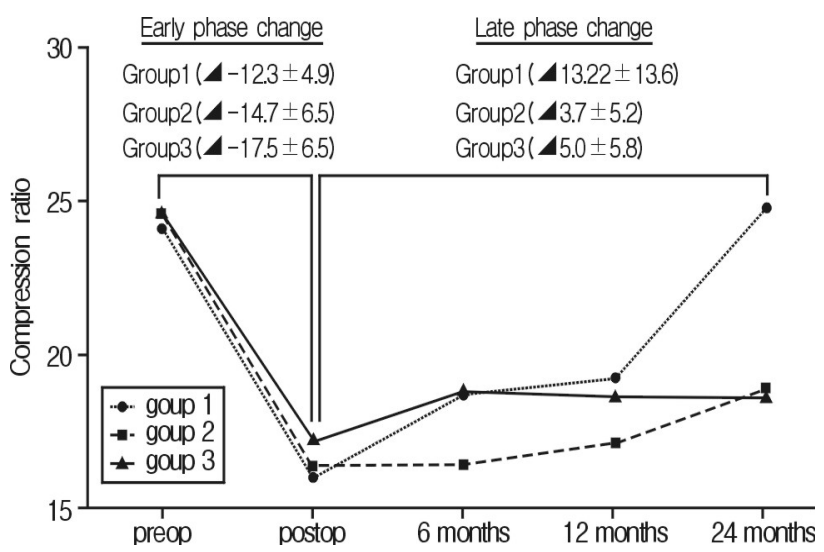

Fig. 4. Changes in compression ratio at the preoperative, postoperative, and 6-, 12-, and 24-month follow-up stages in each group. cally insignificant ( $p>0.05)$ (Fig. 4).

Mean total postoperative and 2-year follow-up kyphotic angles were $-3.6^{\circ}$ and $1.1^{\circ}$, respectively. Mean postoperative and 2-year follow-up changes in kyphotic angle in group 1 were $-4.8^{\circ}$ and $2.2^{\circ}$, group 2 were $-3.9^{\circ}$ and $0.75^{\circ}$, and group 3 were $-2.35^{\circ}$ and $0.7^{\circ}$, respectively. The 2 -year follow-up kyphotic angle was more aggravated in group 1 than in the other groups $(\mathrm{p}<0.05)$ (Fig. 5).

\section{DISCUSSION}

Percutaneous vertebroplasty involves injection of PMMA into a diseased vertebra. The use of vertebroplasty in the treatment of benign or malignant disease has been widely reported $^{21,22,26}$. The effectiveness of percutaneous vertebroplasty in alleviating pain has been discussed comprehensively ${ }^{8,19)}$. However, it has been reported previously that the degree of pain relief is not correlated with other factors such as the volume of injected cement, bone mineral density (BMD), and changes of the compression ratio and kyphotic angle ${ }^{2)}$. In accordance with these studies, we also did not identify a relationship between these factors.

The optimal volume of injected cement is controversial ${ }^{13,14)}$. The larger cement volumes are probably associated with greater risks of complications related to cement leakage, such as intradiscal leakage, epidural or neural foraminal compression, and pulmonary embolism ${ }^{7,25)}$. Some studies reported that only 2 $\mathrm{cc}$ of cement was required to restore strength but that more cement was needed to restore stiffness ${ }^{14)}$, but other studies reported that the magnitude of strength increase varied and was not correlated with the volume of cement injected ${ }^{13)}$. Cement volume was also found to influence adjacent fractures, but less than $5 \mathrm{cc}$ had little effect ${ }^{11,20)}$. In the present study, we injected the cement in 2 aliquots of approximately $3.5 \mathrm{cc}$ each.

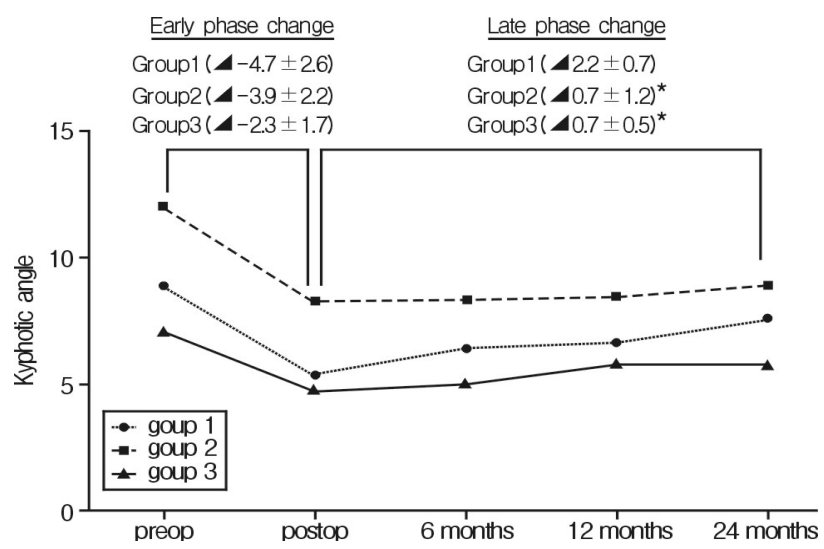

Fig. 5. Changes of kyophotic angle at preoperative, postoperative, and 6-, 12-, 24-month follow-up stages in each group. 
Osteoporosis affects not only one part of the vertebral body but also the whole vertebra; therefore, it is important to stabilize the whole vertebral body. Furthermore, unipedicular distribution of cement in a vertebral body can promote single-sided load transfer and toggle (medial-lateral bending motion), which represents a biomechanically suboptimal result ${ }^{16,17)}$. Therefore, uneven distribution of bone cement in the osteoporotic compression-fractured vertebral body has a risk of additional instability and concomitant danger of adjacent vertebral fractures. Therefore, even cement distribution is critical for long term stability and good outcome of the compressed vertebral body. Our data demonstrate a peri-interventional height gain of the vertebral body, a reduction in kyphotic angle, and an improvement of the compression indices during follow-up over 2 years, particularly in patients in group 3.

Vertebroplasty has been demonstrated to effectively reduce pain. The mean VAS score was 5.2 preoperatively, 1.8 postoperatively, and 3.2 at 2-year follow-up. It was shown that vertebroplasty achieved effective pain reduction in the postoperative period. Furthermore, the follow-up VAS score showed a tendency to increase again. In addition, radiologic findings such as compression ratio and kyphoitic angles showed us similar worsening with changes of VAS score. Therefore, we thought that, pain relief and stabilization of fractured spine in the immediate postoperative period is more significant effect of vertebroplasty. Therefore, we thought that, pain relief and stabilization of fractured spine in the immediate postoperative period is more significant effect of vertebroplasty.

Unfortunately, our study has some limitations. One is the retro- spective study which had been performed by several surgeons. The other is a small number of patients. Because we only inclu- ded patients who underwent serial radiologic evaluations, we could only enroll the small number of patients. This study would be more valid and reliable if more patients performed serial radiologic evaluations were enrolled in this investigation.

\section{CONCLUSION}

Our study did not show a relationship between the clinical and radiologic results in vertebroplasty. The augmented spine tends to be more stable in cases with more even distribution of injected cement. Furthermore, vertebroplasty has a beneficial effect on pain relief and stabilization of fractured spine in the immediate postoperative stage.

\section{REFERENCES}

1. Alanay A, Pekmezci M, Karaeminogullari O, Acaroglu E, Yazici M, Cil A, et al: Radiographic measurement of the sagittal plane deformity in patients with osteoporotic spinal fractures evaluation of intrinsic error. Eur Spine J 16(12):2126-2132, 2007

2. Anselmetti GC, Corrao G, Monica PD, Tartaglia V, Manca A, Eminefendic H, et al: Pain relief following percutaneous vertebroplasty: Results of a series of 283 consecutive patients treated in a single institution. Cardiovasc Intervent Radiol 30(3):441447, 2007

3. Belkoff SM, Mathis JM, Fenton DC, Scribner RM, Reiley ME, Talmadge K: An ex vivo biomechanical evaluation of an inflatable bone tamp used in the treatment of compression fracture. Spine (Phila Pa 1976) 26(2):151-156, 2001

4. Cortet B, Cotten A, Boutry N, Flipo RM, Duquesnoy B, Chastanet $\mathrm{P}$, et al: Percutaneous vertebroplasty in the treatment of osteoporotic vertebral compression fractures: An open prospective study. J Rheumatol 26(10):2222-2228, 1999

5. Cotten A, Duquesnoy B: Vertebroplasty: Current data and future potential. Rev Rhum Engl Ed 64(11):645-649, 1997

6. Cotten A, Boutry N, Cortet B, Assaker R, Demondion X, Leblond D, et al: Percutaneous vertebroplasty: State of the art. Radiographics 18(2):311-320; discussion 320-313, 1998

7. Dean JR, Ison KT, Gishen P: The strengthening effect of percutaneous vertebroplasty. Clin Radiol 55(6):471-476, 2000

8. Deramond H, Depriester C, Galibert P, Le Gars D: Percutaneous vertebroplasty with polymethylmethacrylate. Technique, indications, and results. Radiol Cin North Am 36(3):533-546, 1998

9. Diamond TH, Champion B, Clark WA: Management of acute osteoporotic vertebral fractures: A nonrandomized trial comparing percutaneous vertebroplasty with conservative therapy. Am J Med 114(4):257-265, 2003

10. Evans AJ, Jensen ME, Kip KE, DeNardo AJ, Lawler GJ, Negin GA, et al: Vertebral compression fractures: Pain reduction and improvement in functional mobility after percutaneous polymethylmethacrylate vertebroplasty retrospective report of 245 cases. Radiology 226(2):366-372, 2003

11. Han IH, Chin DK, Kuh SU, Kim KS, Jin BH, Yoon YS, et al: Magnetic resonance imaging findings of subsequent fractures after vertebroplasty. Neurosurgery 64(4):740-744; discussion 744-745, 2009

12. Jensen ME, Evans AJ, Mathis JM, Kallmes DF, Cloft HJ, Dion JE: Percutaneous polymethylmethacrylate vertebroplasty in the treatment of osteoporotic vertebral body compression fractures: Technical aspects. AJNR Am J Neuroradiol 18(10):1897-1904, 1997

13. Kaufmann TJ, Trout AT, Kallmes DF: The effects of cement volume on clinical outcomes of percutaneous vertebroplasty. AJNR Am J Neuroradiol 27(9):1933-1937, 2006

14. Kim DJ, Kim TW, Park KH, Chi MP, Kim JO: The proper volume and distribution of cement augmentation on percutaneous vertebroplasty. J Korean Neurosurg Soc 48(2): 125-128, 2010

15. Legroux-Gerot I, Lormeau C, Boutry N, Cotten A, Duquesnoy B, Cortet B: Long-term follow-up of vertebral osteoporotic fractures treated by percutaneous vertebroplasty. Clin Rheumatol 23(4):310-317, 2004

16. Liebschner MA, Rosenberg WS, Keaveny TM: Effects of bone cement volume and distribution on vertebral stiffness after vertebroplasty. Spine (Phila Pa 1976) 26(14):1547-1554, 2001

17. Luo J, Daines L, Charalambous A, Adams MA, Annesley-Wil- 
liams DJ, Dolan P: Vertebroplasty: Only small cement volumes are required to normalize stress distributions on the vertebral bodies. Spine (Phila Pa 1976) 34(26):2865-2873, 2009

18. Masala S, Mastrangeli R, Petrella MC, Massari F, Ursone A, Simonetti G: Percutaneous vertebroplasty in 1,253 levels: Results and long-term effectiveness in a single centre. Eur Radiol 19(1): 165-171, 2009

19. Mathis JM, Petri M, Naff N: Percutaneous vertebroplasty treatment of steroid-induced osteoporotic compression fractures. Arthritis Rheum 41(1):171-175, 1998

20. Nam JR, Park SB, Ha SI: Subsequent vertebral fracture after percutaneous vertebral augmentation: Adjacent and non-adjacent vertebral fractures. Korean J Spine 6(1):17-21, 2009

21. Peh WC, Gilula LA, Peck DD: Percutaneous vertebroplasty for severe osteoporotic vertebral body compression fractures. Radiology 223(1):121-126, 2002

22. Pitton MB, Koch U, Drees P, Duber C: Midterm follow-up of vertebral geometry and remodeling of the vertebral bidisk unit (vdu) after percutaneous vertebroplasty of osteoporotic vertebral fractures. Cardiovasc Intervent Radiol 32(5):1004-1010, 2009

23. Rho YJ, Choe WJ, Chun YI: Risk factors predicting the new symptomatic vertebral compression fractures after percutaneous vertebroplasty or kyphoplasty. Eur Spine J 21(5):905-911, 2012

24. Shin JH, Jeong JH: Preliminary report of three-dimensional reconstructive intraoperative c-arm in percutaneous vertebroplasty. J Korean Neurosurg Soc 51(2):120-123, 2012

25. Sung DY, Kwon YJ: Technical modification of vertebroplasty. Korean J Spine 5(1):44-47, 2008

26. Weill A, Chiras J, Simon JM, Rose M, Sola-Martinez T, Enkaoua E: Spinal metastases: Indications for and results of percutaneous injection of acrylic surgical cement. Radiology 199(1):241-247, 1996 